\title{
Action-State Orientation: Construct Validity of a Revised Measure and Its Relationship to Work-Related Variables
}

\author{
James M. Diefendorff, Rosalie J. Hall, Robert G. Lord, and Mona L. Strean \\ University of Akron
}

\begin{abstract}
Data from 6 studies $(N=945)$ were combined to examine the factor structure and construct validity of $\mathrm{J}$. Kuhl's (1994a) measure of action-state orientation, the Action Control Scale (ACS). Initial confirmatory factor analysis (CFA) of 4 models showed poor fit with the data. Items that did not perform well were dropped, and the 4 CFA models were retested, resulting in support for a 3-factor solution corresponding to the Preoccupation, Hesitation, and Volatility subscales. Regression analyses demonstrated that the revised ACS subscales measure a construct distinct from cognitive ability and personality. The revised subscales showed differential statistically significant relationships with (a) self-regulatory and self-focus variables and (b) job attitudes and ratings of job performance. The authors conclude that action-state orientation is a construct relevant to applied settings and that future research should further examine this construct.
\end{abstract}

In this study, we explore the measurement and meaning of Kuhl's construct of action-state orientation and demonstrate its relevance to the workplace. At its most general level, action-state orientation is concerned with individual differences in the ability to initiate and maintain intentions (Kuhl, 1994b). The construct reflects the ability to make timely decisions, commit to a course of action, initiate action, avoid procrastination, handle multiple competing demands, maintain challenging goals, and persist despite failures or setbacks (Kuhl \& Beckmänn, 1994). Such volitional behaviors are valued in a variety of life domains, including the workplace, hence our interest in the construct.

Previous research on the action-state construct has contributed substantively to our understanding of self-regulation (Klinger \& Murphy, 1994; Kuhl, 1986a, 1986b, 1992; Kuhl \& Beckmänn, 1985; Kuhl \& Kazén-Saad, 1989; Kuhl \& Kraska, 1989), self-discrimination (Kuhl \& Kazén, 1994a), learned helplessness (Brunstein \& Olbrich, 1985; Kuhl, 1981), depression (Kuhl \& Helle, 1986, 1994; Kuhl \& Kazén, 1994b), decision making (Kuhl, 1986a, 1986b), and academic and athletic performance (Beckmänn \& Kazén, 1994; Strang, 1994). The present investigation assesses the construct validity of the most recent measure of action-state orientation (the Action Control Scale, or ACS-90; Kuhl, 1994a) and examines its relationship with work attitudes and job performance.

\section{Theoretical Background and Definition of Action-State Orientation}

\section{Action-State Orientation in the Context of Theories of Goal-Striving}

Action-state orientation was construed by Kuhl (1994b; Kuhl \& Beckmänn, 1994) as an individual difference variable influencing

James M. Diefendorff, Rosalie J. Hall, Robert G. Lord, and Mona L. Strean, Department of Psychology, University of Akron.

We thank Doug Brown for comments on previous versions of this article and Allen Kamin for access to the Study 6 sample.

Correspondence concerning this article should be addressed to James $\mathbf{M}$. Diefendorff, who is now at the Department of Psychology, Louisiana State University, Baton Rouge, Louisiana 70803. Electronic mail may be sent to jdiefen@1su.edu. volitional processes, or what Lewin, Dembo, Festinger, and Sears (1944) referred to as "goal-striving." Goal-striving refers to the process of implementing a goal and reflects a continuous, dynamic interplay of events and cognitions whereby information is monitored over time, and actions are taken based on changing circumstances (Gollwitzer \& Brandstätter, 1997; Heckhausen \& Gollwitzer, 1987). This emphasis on the implementation of goals has a long history in European (particularly German) research on motivation. Until recently (see Austin \& Vancouver, 1996; Lord \& Levy, 1994), much American research on motivation has focused on issues such as goal choice, goal commitment, and performance outcomes (Hollenbeck \& Klein, 1987; Latham \& Locke, 1991), or what Lewin et al. (1944) termed "goal setting." Goal setting variables are more discrete in nature and are not tied directly to task implementation, but rather they reflect cognitions about the likelihood of achieving a goal or a goal's value. In contrast, goal-striving approaches to motivation are more closely related to issues of the self-regulation of thoughts and actions (Diefendorff et al., 1998; Karoly, 1993; Lord \& Levy, 1994).

Thus, in the context of a broader model of self-regulation, action-state orientation is concerned with characteristic differences in the enactment and maintenance of goals and the ability to protect activated goals from competing action tendencies through information-processing mechanisms such as allocation of attention, inhibition of extraneous cognitions, and emotion control mechanisms (Kuhl, 1994b, Kuhl \& Goschke, 1994). Because of its focus on the dynamic, process-oriented issues of goal-striving, action-state orientation may be useful in understanding why two individuals who have similar goals, knowledge, ability, and desire to perform well nevertheless fail to achieve the same level of performance.

\section{Definition of Action-State Orientation}

Although individuals likely fall on a continuum of action-state orientation, in further describing the characteristic it is helpful to contrast those individuals who are more action oriented versus those who are more state oriented. Individuals with a strong action orientation are able to devote their cognitive resources to the task 250 
goal state to some desired future goal state. These individuals flexibly allocate their attention for the purpose of task execution and goal attainment. Persons who are more action oriented are characterized by enhanced performance efficiency (Kuhl, 1994b) and the ability to complete tasks after minor failures or setbacks. Alternatively, individuals with more of a state orientation tend to have persistent, ruminative thoughts about alternative goals or affective states, which reduces the cognitive resources available for goal-striving. This reduction of available resources impairs state-oriented individuals' ability to initiate activities and to follow tasks through to completion, especially when the activities are difficult, nonroutine, or both. (Brunstein \& Olbrich, 1985; Goschke \& Kuhl, 1993; Kuhl, 1981; Kuhl, 1994b). In addition to the general notion of action-state orientation, Kuhl (e.g., Kuhl \& Beckmänn, 1994) further suggests that three separate aspects or dimensions can be distinguished: preoccupation, hesitation, and volatility.

Preoccupation dimension. This dimension, with opposing poles of preoccupation versus disengagement, indicates the degree to which individuals explicitly process information related to some past, present, or future state. The action-oriented pole of this dimension (disengagement) refers to the ability to detach from thoughts about alternative goals or undesirable events that may interfere with progress on the task at hand. In contrast, the stateoriented pole is associated with impaired effectiveness due to the perseveration of thoughts related to some unpleasant experience (real or simulated), often involving failure (Kuhl, 1994a).

Hesitation dimension. This dimension, with opposing poles of hesitation versus initiative, refers to the degree to which individuals have difficulty initiating intended goal-directed activities. Action-oriented individuals on this dimension (initiative pole) are able to easily initiate work on tasks. Although both the hesitation and the preoccupation dimensions are similar in their focus on the ability to move forward with tasks and to escape from stateoriented processing when necessary, they have different bases. Specifically, the preoccupation dimension is concerned with whether distracting thoughts interfere with initiating action, whereas the hesitation dimension emphasizes the behavioral capacity to initiate action.

Volatility dimension. This dimension, with opposing poles of volatility versus persistence, is concerned with the ability to stay in the action-oriented mode when necessary. It refers to the degree to which individuals become distracted when working on an interesting or necessary task. More action-oriented individuals (persistence pole) are able to effectively maintain focus on an intention until the task is complete, whereas more state-oriented individuals are easily pulled off-task, impairing their overall performance. State-oriented processing associated with the volatility dimension may be due to an overactivity of the action initiation system (and hence a tendency to inappropriately initiate new tasks), rather than the underactivity of this system seen in the state-oriented poles of the preoccupation and hesitation dimensions (Kuhl, 1994a).

Thus, the three action-orientation dimensions relate to different facets of the goal-striving process. Action-oriented individuals flexibly disengage from irrelevant concerns (preoccupation), effectively initiate required actions (hesitation), and stay focused until tasks are completed (volatility).
Proposed Relationships of Action-State Orientation With Work Variables

\section{Expected Relationship With Job Performance and Job Attitudes}

To date, no published study has examined the relationship between action-state orientation and work-related outcomes. Because a key aspect of most jobs is the initiation and maintenance of productive behavior, it is likely that individual differences in action-state orientation are related to job performance. Holding other relevant individual characteristics such as ability, knowledge, and experience equal, employees who are more actionoriented should complete more assigned tasks, have less difficulty meeting deadlines, and because of their more effective allocation of cognitive and emotional resources to the task, produce higher quality outputs. This relationship should hold at least as strongly for discretionary tasks in the workplace, such as organizational citizenship behaviors (OCBs). Because OCBs are more voluntary, there are fewer structural mechanisms such as production goals or company procedures and policies built into the workplace to guard against self-regulatory failure. Thus performance of OCBs is expected to be more dependent on self-regulatory mechanisms internal to the individual employee.

Thus, in general, we expect a moderate, positive relationship between action-state orientation and supervisor ratings of job performance, indicating that more action-oriented employees perform better. This relationship should hold regardless of whether the performance ratings are for required job behaviors or for more voluntary behaviors such as OCBs. To the extent that higher performance leads to more tangible and intangible, benefits, such as monetary rewards, social recognition, and personal competence, it is additionally expected that action-state orientation will also be positively related to job attitudes such as job satisfaction, work centrality, and job involvement.

\section{Relationships Supporting a Self-Regulatory Explanation of Effects}

The arguments that we advance for expecting action-state orientation to be related to job performance and job attitudes assume mechanisms based on volitional, self-regulatory processes. Thus it is theoretically important not only to demonstrate that the relationships exist, but to find additional corroborative evidence specifically supporting a self-regulatory explanation and to rule out alternative interpretations of the observed relationships in terms of other constructs such as cognitive ability or personality. Thus, the current study also investigates the relationships of action-state orientation with a variety of individual difference variables, including self-regulatory, cognitive, and personality variables. Measures of action-state orientation should (a) show significant relationships with related self-regulatory variables, (b) be essentially unrelated to general and specific cognitive abilities, and (c) relate to work performance and job attitudes above and beyond variance explained by personality variables. The specific self-regulatory, cognitive ability, and personality variables investigated are described in Table 1, and the hypothesized relationship for each set of variables is listed in Table 2 . 
Table 1

Description and Definition of Focal Variables by Study

\begin{tabular}{|c|c|c|c|c|}
\hline Variable measured $^{\mathrm{a}}$ & Response format & $\begin{array}{l}\text { No. of } \\
\text { items }\end{array}$ & $\alpha$ & Construct definition \\
\hline \multicolumn{5}{|l|}{ Study $1(n=96)$} \\
\hline $\begin{array}{l}\text { Self-Consciousness Scale (Fenigstein, Scheier, } \\
\text { \& Buss, 1975) }\end{array}$ & $\begin{array}{l}\text { Self-report; } \\
\text { 5-point Likert }\end{array}$ & & & The extent to which attention is focused on the following: \\
\hline Private & & 10 & .53 & internal aspects of the self; \\
\hline Public & & 7 & .78 & the self as a social object; \\
\hline Social Anxiety & & 6 & .53 & $\begin{array}{l}\text { feelings of apprehensiveness over being evaluated in a social } \\
\text { context. }\end{array}$ \\
\hline $\begin{array}{l}\text { Cognitive Failures Questionnaire (CFQ; } \\
\text { Broadbent, Cooper, FitzGerald, \& } \\
\text { Parkes, 1982) }\end{array}$ & $\begin{array}{l}\text { Self-report; } \\
\text { 5-point Likert }\end{array}$ & 25 & .87 & $\begin{array}{l}\text { Everyday failures in perception, memory, and motor } \\
\text { functioning. }\end{array}$ \\
\hline $\begin{array}{l}\text { Negative priming (Kane, Hasher, Stoltzfus, } \\
\text { Zacks, \& Connelly, 1994) }\end{array}$ & Reaction times & - & - & Cognitive inhibition. \\
\hline \multicolumn{5}{|l|}{ Study $2(n=71)$} \\
\hline Negative priming (Kane et al., 1994) & See Study 1 & & & \\
\hline CFQ (Broadbent et al., 1982) & See Study 1 & & & \\
\hline WAIS-R Information (Wechsler, 1981) & Verbal response & - & - & General mental ability. \\
\hline WAIS-R Digit Span (Wechsler, 1981) & Verbal response & - & - & Short-term memory capacity. \\
\hline \multicolumn{5}{|l|}{ Study $3(n=56)$} \\
\hline $\begin{array}{l}\text { Thought Occurrence Questionnaire (Sarason, } \\
\text { Sarason, Keefe, Hayes, \& Shearin, 1986) }\end{array}$ & $\begin{array}{l}\text { Self-report; } \\
\text { 5-point Likert }\end{array}$ & & & $\begin{array}{l}\text { General tendency to misappropriate attention while working on } \\
\text { tasks to thoughts: }\end{array}$ \\
\hline Off-Task & & 11 & .85 & regarding emotions and social relations; \\
\hline Escape & & 7 & .84 & about escape from the task; \\
\hline Task-Related & & 9 & .76 & about task-relevant worries. \\
\hline $\begin{array}{l}\text { Cognitive Interferences Questionnaire } \\
\text { (Sarason et al., 1986) }\end{array}$ & $\begin{array}{l}\text { Self-report; } \\
\text { 5-point Likert }\end{array}$ & 22 & .89 & $\begin{array}{l}\text { Frequency of intrusive thoughts while working on a just- } \\
\text { completed task. }\end{array}$ \\
\hline \multicolumn{5}{|l|}{ Study $4(n=131)$} \\
\hline Beck Depression Inventory (Beck, 1978) & $\begin{array}{l}\text { Self-report; forced } \\
\text { choice }\end{array}$ & 21 & .87 & Acute depressive symptoms. \\
\hline $\begin{array}{l}\text { Marlowe-Crowne Social Desirability Scale } \\
\text { (SDS; Crowne \& Marlowe, 1960) }\end{array}$ & $\begin{array}{l}\text { Self-report; true- } \\
\text { false }\end{array}$ & 33 & .79 & Tendency to present oneself in a favorable light. \\
\hline Study $5(n=344)$ & & & & \\
\hline $\begin{array}{l}\text { Marlowe-Crowne SDS (Crowne \& Marlowe, } \\
\text { 1960) }\end{array}$ & See Study 4 & & & \\
\hline \multicolumn{5}{|l|}{ Study $6(n=247)$} \\
\hline Adjective Checklist (Goldberg, 1992) & $\begin{array}{l}\text { Self-report; } \\
\text { 7-point Likert }\end{array}$ & & & The Big Five personality dimensions: \\
\hline Extraversion & & 20 & .88 & Energetic, outgoing, bold; \\
\hline Agreeableness & & 20 & .89 & Friendly, considerate, warm; \\
\hline Dependability & & 20 & .90 & Responsible, cautious, thorough; \\
\hline Emotional Stability & & 20 & .84 & Calm, relaxed, poised; \\
\hline Intellect & & 20 & .88 & Imaginative, knowledgeable, perceptive. \\
\hline $\begin{array}{l}\text { Job in General Scale (Ironson, Smith, } \\
\text { Branick, Gibson, \& Paul, 1989) }\end{array}$ & $\begin{array}{l}\text { Self-report; } \\
\text { 7-point Likert }\end{array}$ & 18 & .95 & General job satisfaction. \\
\hline $\begin{array}{l}\text { Neutral Objects Satisfaction Questionnaire } \\
\text { (Weitz, 1952) }\end{array}$ & $\begin{array}{l}\text { Self-report; } \\
\text { 3-point Likert }\end{array}$ & 25 & .79 & $\begin{array}{l}\text { Affective disposition; level of satisfaction with everyday } \\
\text { objects. }\end{array}$ \\
\hline $\begin{array}{l}\text { Job involvement (Paullay, Alliger, \& Stone- } \\
\text { Romero, 1994) }\end{array}$ & $\begin{array}{l}\text { Self-report; } \\
\text { 7-point Likert }\end{array}$ & & & $\begin{array}{l}\text { Extent to which one is cognitively preoccupied with or } \\
\text { engaged in the following: }\end{array}$ \\
\hline Role & & 14 & .88 & the tasks of one's job; \\
\hline Setting & & 13 & .89 & the environment that one works in. \\
\hline Work centrality (Paullay et al., 1994) & $\begin{array}{l}\text { Self-report; } \\
\text { 7-point Likert }\end{array}$ & 12 & .79 & Degree of importance that work plays in one's life. \\
\hline $\begin{array}{l}\text { In-role job performance (Williams \& } \\
\quad \text { Anderson, 1991) }\end{array}$ & $\begin{array}{l}\text { Supervisor rating; } \\
\text { 7-point Likert }\end{array}$ & 7 & .57 & $\begin{array}{l}\text { How well individuals perform activities specified in their job } \\
\text { description. }\end{array}$ \\
\hline $\begin{array}{l}\text { Organizational Citizenship Behavior } \\
\text { Questionnaire (Podsakoff, MacKenzie, } \\
\text { Moorman, \& Fretter, 1990) }\end{array}$ & $\begin{array}{l}\text { Supervisor rating; } \\
\text { 7-point Likert }\end{array}$ & & & $\begin{array}{l}\text { Discretionary, work-related behaviors not part of an } \\
\text { individual's job description. These behaviors take the form } \\
\text { of: }\end{array}$ \\
\hline Conscientiousness & & 5 & .80 & going beyond performance expectations; \\
\hline Sportsmanship & & 5 & .88 & not complaining about small issues; \\
\hline Courtesy & & 5 & .86 & preventing problems for others; \\
\hline Altruism & & 5 & .85 & assisting others with existing problems; \\
\hline Civic Virtue & & 4 & .81 & involvement in the political life of company. \\
\hline Grade point average & Self-report & - & - & Success in academic domain. \\
\hline
\end{tabular}

Note. Dashes indicate that the data were not applicable. WAIS-R $=$ Wechsler Adult Intelligence Scale-Revised.

${ }^{2}$ Action-state orientation was measured with the ACS-90 in all six studies and thus was not included in the table. Its characteristics are further described in the text. 
Table 2

Expected Relationships With Cognitive Ability, Self-Regulatory, Personality, and Work Variables

Variable

Cognitive ability variables (Studies 1,2 , and 6): WAIS-R Information subtest, WAIS-R Digit Span subtest, negative priming, and grade point average.

Self-focus and self-regulatory variables (Studies 1-4); Self-Consciousness Scale, Beck Depression Inventory, Thought Occurrence Questionnaire, Cognitive Interference Questionnaire, and Cognitive Failures Questionnaire.

Personality and affective variables (Study 6):

Big Five personality factors and dispositional affect.

Social desirability (Studies 4 and 5).

Job attitudes and supervisory performance ratings (Study 6): Job satisfaction, job involvement, work centrality, supervisory ratings of in-role performance, and supervisor ratings of OCBs.
Hypothesized effects and rationale

These variables were included to test the discriminant validity of the ACS subscales. It was anticipated that there would be small to zero correlations between the cognitive ability variables and the ACS subscales.

These variables were examined to demonstrate the convergent validity of the ACS subscales and further substantiate the nomological network of the action-state orientation construct. It was expected that these measures would be significantly related to the ACS subscales.

These variables were included to examine their degree of overlap with action-state orientation. It was expected that although personality and affect may significantly relate to the ACS subscales, there would still be a substantial proportion of unshared variance.

It was anticipated that this variable would be positively related to the ACS subscales.

These variables were included to examine the usefulness of action-state orientation for predicting work-related attitudes and supervisor ratings of performance. It was anticipated that the ACS subscales would significantly predict the work-related outcomes, even after the effects of relevant demographic and personality variables were removed.

Note. $\quad$ ACS $=$ Action Control Scale; WAIS-R $=$ Wechsler Adult Intelligence Scale-Revised; OCBs = Organizational Citizenship Behavior Questionnaires.

\section{Measurement of Action-State Orientation: The Action Control Scale (ACS)}

\section{Description of the ACS}

The ACS (German version is the HAKEMP) is a forced-choice self-report measure developed by Kuhl (1985) to assess differences in action-state orientation. The items on the scale depict brief scenarios that occur in everyday life and require selection of one of two options that indicate what the participant would do. Since its original development, the ACS has gone through three revisions, the most recent version being the ACS-90. The ACS -90 consists of 36 items, divided equally into three subscales measuring preoccupation, hesitation, and volatility (Kuhl \& Beckmänn, 1994).

\section{Issues in the Factor Structure of the ACS}

There are conflicting views of the factor structure of the ACS. Exploratory factor analyses of the ACS-90, reported in Kuhl (1994a), resulted in the extraction of three factors with sizeable eigenvalues, rather than a single action-state orientation factor. These factors correspond to the preoccupation, hesitation, and volatility concepts described earlier. On the basis of these factor analysis results, one would conclude that hypotheses involving action-state orientation should be tested using all three ACS subscales so that unique relationships with the three distinct aspects of action-state orientation can be detected. Yet theoretical work (e.g., Kuhl, 1994b) frequently treats action-state orientation as a unitary underlying tendency, and it may be argued that a single action-state composite score, combining all 36 ACS items, would be sufficient to capture the construct. Empirical work shows that a composite ACS -90 score based on all three subscale items has adequate internal consistency. Thus, both theoretical and empirical evidence exist for considering the ACS to have both a one- and a three-factor structure.

A third, intermediate possibility, is that the Preoccupation and Hesitation subscales measure a single construct, whereas the Volatility subscale measures a second construct. This interpretation is also based on both empirical results and theory. Observed correlations between the Preoccupation and Hesitation subscales are typically quite high, whereas their correlations with the Volatility subscale are typically close to zero (Kuhl, 1994a, 1994b). This pattern of relationships is consistent with Kuhl's idea that the ability to escape the state-oriented mode of processing, when necessary, may be independent of the ability to remain in an action-oriented mode of processing, when desired.

Further complicating the issue, a study by Kanfer, Dugdale, and McDonald (1994) in part replicates Kuhl's (1994b) finding of a three-factor structure, but also finds some evidence supporting a more complex five-factor structure. Their five-factor structure subdivided the Hesitation subscale into a planning dimension (extent of constructive problem-solving) and a Discipline dimension (the ease of initiation of boring or unpleasant tasks). It also subdivided the volatility subscale into a Persistence dimension and an Absorption dimension (reflecting the extent to which an individual becomes caught up in the task). The Preoccupation subscale stayed essentially intact.

In sum, previous empirical and theoretical works have implied several a priori competing models of the ACS factor structure. The first and most parsimonious of these models is a one-factor model which is consistent with the idea of a global, unitary action-state orientation construct. The second model, a two-factor model, suggests that there are two latent constructs influencing ACS responses - the ability to escape the state-oriented mode of processing (assessed by preoccupation and hesitation items) and the ability to stay in the action-oriented mode of processing (assessed 
by volatility items). The third a priori model, a three-factor model, is implied by most previous empirical and theoretical work with the ACS measure, and suggests that preoccupation, hesitation, and volatility are separate constructs. Finally, the fourth a priori model is the five-factor model suggested by Kanfer et al.'s (1994) exploratory factor analyses.

Thus, the current study first examines the ACS-90 from a construct-validation perspective. Whether the concept of actionstate orientation contributes to research in work settings depends in part on the construct validity of its measure. Because construct validity is so essential to both the research process and applied work, attention to it before a variable makes substantial impact on a field may help avoid unwarranted substantive conclusions, erroneous bodies of research, and unsuitable applications (Schwab, 1980). Given strong a priori models, we believed that the competing hypothesized factor structures could be assessed and compared with confirmatory factor analysis (CFA) techniques to address the construct validity question.

\section{Overview}

The present study attempts to broaden our understanding of action-state orientation and to demonstrate its relevance for organizational settings. To do this, we report the results of six empirical studies that address three main issues: (a) a confirmatory factor analytic assessment of the dimensionality of the action-state orientation construct as measured by the ACS-90, (b) expansion of the nomological net of relationships supporting the action-state construct through establishing convergent validity with other selfregulatory measures and discriminant validity with cognitive ability and personality measure, and (c) a demonstration of the relationships of action-state orientation with work attitudes and supervisor ratings of job performance.

\section{Method}

\section{Participants}

Volunteer participants from Introductory Psychology classes were recruited for each of the six studies. In return for their participation, they received extra credit points. In all six studies, participants completed the 36-item, forced-choice ACS-90 (Kuhl, 1994a) in addition to other measures described in Table 1. Study 1 had 96 participants (28 male and 68 female) with an average age of 25.6. Study 2 had 71 participants (26 male and 45 female) with an average age of 21.6. Diefendorff et al. (1998) used these samples to show the relation of negative priming and the ACS-90 to self-reports of self-regulatory success in everyday life.

Study 3 had 56 participants. Age and gender information were not collected for this study, but the participants were sampled from the same subject pool as the other studies included in this article. This sample was used as a pilot study for Strean (1999). Study 4 had 131 participants (32 male, 75 female, and 24 unknown) with a mean age of 24.4 years. Study 5 had 344 participants ( 81 male, 235 female, and 28 unknown) with a mean age of 23.6 years. Studies 4 and 5 were part of a larger research project described in Strean.

The data for Study 6 were collected as part of a larger study by Kamin (1999) examining the role of attitude accessibility on the attitude-behavior relationships. Participants were 247 employed students (88 male, 156 fernale, and 3 unknown). The mean age for this sample was 24.4 years with an average tenure of 3 years at the present job. In addition to completing several self-report measures, participants gave permission for questionnaires assessing in-role job performance and OCBs to be sent to their supervisors. Participants' supervisors received a packet of questionnaires with a letter of explanation, instructions for filling out the questionnaires, and a self-addressed, stamped envelope to return their ratings. The return rate for the supervisory ratings was $55 \%$.

\section{Measures}

The ACS-90 and a variety of cognitive ability, self-regulatory, personality, job performance, and work attitude measures were administered (see Table 1 for more detail). As described earlier, the ACS-90 consists of 36 dichotomous items, with 12 items each in the Preoccupation, Hesitation, and Volatility subscales (see the Appendix for item stems and responses) High scores on the three scales indicate greater action-orientation (thus low scores indicate greater state-orientation).

\section{Treatment of Missing Responses and Outlier Screening}

The data from all six studies were combined into one large data set for the CFA. Of the 946 participants in the combined data set, one individual was missing responses to 8 items of the ACS-90 and was dropped from further analysis, reducing the sample size to 945 . An additional 17 persons were missing responses for up to four items. For these persons, multiple regression was used to impute replacement values based on responses to the remaining items in the relevant ACS subscale. In total, 28 missing data points were imputed out of 34,020 (less than $1 \%$ ).

Prior to performing the correlation and multiple regression analyses, all relevant variables in the studies were screened for univariate and multivariate outliers (Tabachnick \& Fidell, 1996). This procedure resulted in the identification of a small number of outliers, which were then removed from relevant analyses. The number of participants dropped from any one analysis because of outliers ranged from 0 to 8 , with $7 \%$ of the sample being the maximum percentage removed from any one analysis.

\section{Results and Discussion}

\section{Results of CFAs}

CFAs were performed to determine whether a one-, two-, three-, or five-factor solution best fit the ACS items. LISREL 8.14 (Jöreskog \& Sörbom, 1993) was used to test the CFA models. The item-level indicators consisted of dichotomous responses, therefore an estimation method that did not require a normality assumption was required. To address this issue, PRELIS 2.14 was used to generate an asymptotic covariance matrix for input to the LISREL analysis, then a weighted least squares (WLS) procedure was used to estimate the model parameters, following the example described in Jöreskog and Sörbom (1989, pp. 233-235).

Description of factor models and initial analyses. We used CFA to compare four factor structures, implied by previous theory and empirical research: Model A, a one-factor model; Model B, a two-factor model combining Kuhl's Hesitation and Preoccupation scales into a single factor, but retaining the original Volatility scale as a separate factor; Model C, Kuhl's three-factor model; and Model D, Kanfer et al.'s five-factor model.

For each CFA model, a single path was freed from the relevant factor to each item. No cross-loadings were allowed. All models containing more than one factor were oblique-that is, latent factors were allowed to freely intercorrelate. For all models, the metric was set by fixing factor variances to 1.0. Models A, B, and $C$ were nested, thus their fits could be compared directly using chi-square difference tests. Comparisons to the nonnested Model D were made using the comparative fit index (CFI). 
An initial set of analyses of Models A-D was performed, using all 12 items from each of the three ACS subscales. The results showed that none of the models fit the data especially well. The five-factor model did not converge after 500 iterations, often a sign of an incorrectly specified model. For all four models, the chisquare goodness-of-fit statistic was significant $(p<.001)$, thus leading to the rejection of the null hypothesis of good fit. Rootmean-square error of approximation (RMSEA) values were all larger than .06; standardized root-mean-square residual (SRMR) values ranged from .20 to .21 , and all values of fit indices were below .90 . Recently recommended "rules of thumb" for fit indices suggest cutoff values of at least .95 for the Tucker-Lewis index (TLI) and CFI, and, at most, .06 for the RMSEA (Hu \& Bentler, 1999). Furthermore, these authors found that the sum of Type I and Type II error rates is lowest when decisions to reject or retain models are made on the basis of combinations of fit indices. Specifically, Hu and Bentler suggested that combined criteria be used when making a decision whether to reject a model. They recommended two possible combination rules. The first combinational rule is to reject the model when RMSEA $>.06$, and SRMR $>.09$. The second combinational rule is to reject the model when TLI $<.96$, and SRMR $>.09$. Because all four models would clearly be rejected by either of these rules, and in the interests of saving space, these results are not detailed further.

Instead, the LISREL residuals and modification indices from these analyses were inspected for clues about the sources of poor model fit. The modification indices suggested that a large decrease in the model misfit could be achieved by allowing the residual error terms $\left(\theta_{\delta} s\right)$ of two Hesitation subscale items (Items 26 and 35) with identical response options to correlate with each other. The models were respecified including the correlated residuals and reestimated. However, the resulting fit was still poor for all four models after reestimation (see the summarized results in the top portion of Table 3). For all models tested, the chi-square goodnessof-fit statistic was still significant, $p<.001$. RMSEA values were still all greater than .06 , and fit indices were still less than .90 . The five-factor model (Model D) still showed convergence problems.

Tests comparing the fit of the four models were not performed for the analyses using a full set of ACS items because (a) the relatively poor overall fit of all four models tested in this set of analyses, and (b) indications of some poor quality items, including low factor loadings $\left(\lambda_{x} s\right)$ and/or modification indices suggesting substantial cross-loadings on secondary factors. (See the Appendix for values of factor loadings and the specific items.) Items with loadings of less than .40 , indications of substantial secondary factor influence, or both, were identified and dropped from the item pool. This eliminated four items each from the Preoccupation scale (Items 1, 7, 16, and 25) and the Hesitation scale (Items 14, $17,23,32$ ), and six items from the Volatility scale (Items $6,9,12$, 18,27 , and 30). The four CFA models were retested on the revised set of 22 items.

CFA results: Revised item set. The models using the revised item set yielded a noticeably better fit to the data than did the first set of analyses. The chi-square goodness-of-fit tests were still statistically significant for all models tested, resulting in a rejection of the null hypothesis of "good fit." (See lower portion of Table 3.) However, because of the large sample size used in the current study, the chi-square statistic is extremely sensitive to minor model misfit, and relatively well-fitting models may in fact show statistical significance. Thus information from other indicators of fit was assessed.

The RMSEA was below .05 for the three-factor model $($ RMSEA $=.037)$ and the two-factor model (RMSEA $=.045)$, and below .06 for the one- and five-factor models, indicating at least adequate fit for all four models based on this criterion (see Table 3). The goodness-of-fit index (GFI) values for all except the one-factor model were greater than .95 . The better fit of all models in this set of analyses justified making comparisons among them.

Comparisons among Models A, B, and C were made in two ways: (a) using the chi-square difference test, and (b) comparing values of the CFI. Beginning with a comparison of the two most parsimonious models, the chi-square difference test and CFI results both indicated that the two-factor model fit significantly better than the one-factor model, $\Delta \chi^{2}(1, N=945)=251.71, p<$ $.001, \Delta C F I=.08$. In turn, the three-factor model fit significantly better than the two-factor model, $\Delta \chi^{2}(2, N=945)=141.81, p<$ $.001, \Delta C F I=.04$. Because the five-factor model was not part of a nested sequence, this model was compared with the three-factor

Table 3

Summary of Fit Tests for Confirmatory Factor Analysis Models

\begin{tabular}{lccccccc}
\hline \multicolumn{1}{c}{ Model } & $\chi^{2}(N=945)$ & $d f$ & RMSEA & SRMR & GFI & TLI & CFI \\
\hline Set 1: Models with 36 items & & & & & & & \\
A. 1-factor & $4,232.64^{* * *}$ & 593 & .081 & .19 & .86 & .70 & .72 \\
B. 2-factor & $4,147.62^{* * *}$ & 592 & .080 & .19 & .86 & .71 & .73 \\
C. 3-factor & $4,085.01^{* * *}$ & 590 & .079 & .19 & .87 & .71 & .73 \\
D. 5-factor & $4,295.81^{* * *}$ & 583 & .082 & .16 & .86 & .69 & .72 \\
Set 2: Models with 22 items & & & & & & & \\
A. 1-factor & $861.29^{* * *}$ & 208 & .058 & .15 & .94 & .76 & .79 \\
B. 2-factor & $609.58^{* * *}$ & 207 & .045 & .11 & .96 & .85 & .87 \\
C. 3-factor & $467.77^{* * *}$ & 205 & .037 & .087 & .97 & .90 & .91 \\
D. 5-factor & $655.54^{* * *}$ & 198 & .050 & .12 & .95 & .82 & .85 \\
\hline
\end{tabular}

Note. For all models, the errors of Items 26 and 35 were allowed to covary. RMSEA $=$ root-mean-square error of approximation; SRMR = standardized root-mean-squared residual; GFI = goodness-of-fit index; TLI = Tucker-Lewis index; CFI = comparative fit index.

a This model failed to converge after 500 iterations; reported fit values are based on the preliminary solution. $* * * p<.001$. 
model using the CFI values, which suggested that the three-factor model had the better fit $(\Delta C F I=.06)$. Thus, on the basis of the chi-square difference tests, comparisons of CFI, and the low value of its RMSEA, the best-fitting model was unambiguously the three-factor model. Furthermore, this is the only model that would be retained if $\mathrm{Hu}$ and Bentler's (1999) TLI-SRMR combinational rule were used. Finally, the three-factor model also has the advantage of previous theoretical and empirical validation.

\section{Developing the Nomological Net for the Revised ACS Subscales}

The next section presents the results of multiple regression and correlation analyses, used to develop evidence of the nomological network for action-state orientation and to provide evidence of its usefulness in applied settings. These analyses were performed using the ACS subscale scores based on both the full and revised item sets, but for the sake of brevity, we report only the results based on the revised item set. This decision was made on the bases of (a) relatively high correlations between the original and revised subscale scores (see Table 4), and (b) the previously described CFA results suggesting that the revised subscales may more cleanly measure the subcomponents of action-state orientation than the original subscales. The revised subscales showed slightly lower estimates of internal consistency reliability (alpha) than did the original subscales, as can be seen from Table 4, but this did not appear to damage validities. The correlation and regression analyses with the subscales, based on the full versus revised item sets, yielded similar results ( $79 \%$ of the parameter estimates varied by no more than .05), but in over $70 \%$ of the analyses, the original subscales explained less variance than did the revised subscales.

\section{Relationships of the Revised ACS Subscales With Cognitive Ability Variables}

To examine whether action-state orientation is redundant with cognitive ability, the revised ACS subscales were correlated with measures of cognitive inhibition (negative priming), short-term memory capacity (Wechsler Adult Intelligence Scale-Revised, or WAIS-R; Digit Span), general intelligence (WAIS-R, Information), and academic success (grade point average). The correlations ranged in value from -.09 to .13 , and none were statistically significant (further detail is available from James M. Diefendorff).

Table 4

Correlations Among the Original and Revised ACS Subscales

\begin{tabular}{lllc}
\hline ACS subscale & 1 & 2 & 3 \\
\hline 1. Preoccupation & $.95^{* * *}$ & $.43^{* * *}$ & -.03 \\
2. Hesitation & $.39^{* * *}$ & $.9^{* * *}$ & $.18^{* * *}$ \\
3. Volatility & .01 & $.19^{* * *}$ & $\mathbf{. 8 7 ^ { * * * }}$ \\
\hline
\end{tabular}

Note. Correlations between the original and revised subscale are in boldface. Values above (below) the diagonal are for the original (revised) Action Control Scale (ACS) subscales. Values on the diagonal are the correlations between the original and revised versions of the subscale. Alphas for the original (and revised) subscales are as follows: for Preoccupation, .71 (.66); for Hesitation, .75 (.74); and for Volatility, .56 (.51). $* * * p<.001$.
These results effectively demonstrate the discriminant validity of action-state orientation with respect to cognitive ability.

\section{Relationships of the Revised ACS Subscales With Self-Focus and Self-Regulatory Variables}

Relationships with self-consciousness. The three Self-Consciousness Scale (SCS) subscales measure the extent to which an individual focuses his or her attention on different aspects of the self, thus reflecting the extent of self-rumination. The relationships between the SCS subscales and the revised ACS subscales were examined using a set of multiple regressions that modeled the revised ACS subscales as predictors of the SCS subscales (see Table 5). Between $15 \%$ and $22 \%$ of the variance in each of the three SelfConsciousness subscales was explained by the set of the three ACS predictors. In all three models, most of the variance explained was due to the Preoccupation scale's significant negative relationships: Public $(\beta=-0.39, p<.001)$, Private $(\beta=-0.40, p<.001)$, and Social Anxiety subscales, $(\beta=-0.35, p<.001)$, indicating that individuals who were more state-oriented reported greater focus on the self. The nonsignificant relationships of the Hesitation and Volatility subscales with self-consciousness makes sense, given that these constructs are more closely related to overt actions (initiating activities and maintaining task effort, respectively), whereas the Preoccupation scale is concerned with thoughts.

Relationships with depressive thinking. Results show that depressive symptoms, as measured by the Beck Depression Inventory (BDI), are predicted by action-state orientation. About $24 \%$ of the variance in BDI scores is explained by the three ACS subscales, with the Preoccupation and Volatility subscales showing significant unique relationships (see Table 6). The significant negative relationship between the BDI and the Preoccupation subscale $(\beta=-0.35, p<.001)$ suggests that persons who think more about task failures or alternative goals also tend to be more depressed. In addition, the significant negative relationship with the Volatility subscale $(\beta=-0.27, p=.001)$ suggests that experiencing distractions or being unable to finish tasks is associated with more depressive symptoms.

Relationships with measures of thought intrusions. Regression models with the revised ACS subscales as predictors and the Thought Occurrence Questionnaire (TOQ) subscales as the dependent variables explained between $16 \%$ and $31 \%$ of the variance in the TOQ and were all statistically significant (see Table 5). These results suggest that in general, state-oriented individuals are more likely to have off-task thoughts, thoughts of escaping from tasks, and task-relevant worries than are action-oriented individuals. Interestingly the individual ACS subscales differentially predicted different types of thought intrusions. The Preoccupation subscale predicted the occurrence of off-task concerns related to emotional or social issues $(\beta=-0.38, p=.01)$, whereas the Hesitation subscale predicted the occurrence of thoughts regarding escape from tasks $(\beta=-0.29, p=.04)$, and marginally predicted task-related thoughts $(\beta=-0.26, p=.09)$. Similarly, a regression of the three revised ACS subscales on the Cognitive Interferences Questionnaire (CIQ) resulted in a significant negative effect for the Hesitation subscale $(\beta=-0.32, p=.03$ ), suggesting that stateoriented individuals are more likely to report that they incurred thought intrusions during performance of a recently completed task than are action-oriented individuals. 
Table 5

Regression of Self-Focus and Self-Regulatory Variables on Revised Action Control Scale Subscales

\begin{tabular}{lrllll}
\hline & \multicolumn{5}{c}{ Standardized regression coefficient } \\
\multicolumn{1}{c}{ Dependent variable } & $n$ & Preoccupation & Hesitation & Volatility & Full model $R^{2}$ \\
\hline Self-Consciousness Scale & & & & & \\
$\quad$ Public & 93 & $-.39^{* * *}$ & -.13 & -.03 & $.22^{* * *}$ \\
$\quad$ Private & 93 & $-.40^{* * *}$ & .16 & -.07 & $.15^{* *}$ \\
$\quad$ Anxiety & 93 & $-.35^{* *}$ & -.04 & -.04 & $.15^{* *}$ \\
Beck Depression Inventory & 130 & $-.35^{* * *}$ & -.08 & $-.27^{* *}$ & $.24^{* * *}$ \\
Thought Occurrence Questionnaire & & & & & \\
$\quad$ Off-Task & 55 & $-.38^{*}$ & -.11 & .18 & $.18^{*}$ \\
$\quad$ Escape & 55 & -.20 & $-.29^{*}$ & $-.23 \dagger$ & $.31^{* * *}$ \\
$\quad$ Task-Related & 55 & -.21 & $-.26 \dagger$ & .04 & $.16^{*}$ \\
Cognitive Interference Questionnaire & 53 & -.21 & $-.32^{*}$ & -.04 & $.17^{* *}$ \\
Cognitive Failures Questionnaire & 165 & .07 & $-.30^{* * *}$ & -.08 & $.13^{* * *}$ \\
\hline
\end{tabular}

$\dagger p<.10$ (marginally significant). ${ }^{*} p<.05 .{ }^{* *} p<.01 .{ }^{* * *} p<.001$.

Relationships with cognitive failures. We found that actionoriented individuals reported fewer cognitive failures than stateoriented individuals, with the set of three ACS predictors explaining about $13 \%$ of the variance in the Cognitive Failures Questionnaire (CFQ) scores. The only significant regression coefficient was for the Hesitation subscale $(\beta=-0.30, p<.001)$, suggesting that the ability to initiate activities is particularly relevant for avoiding everyday thought-related failures (see Table 5).

Summary of relationships of ACS with self-focus and selfregulation measures. The significant results of the regression analyses of the self-focus and self-regulation variables provide convincing evidence that the revised ACS subscales measure constructs relevant to volition or goal-striving. As a block, the revised ACS subscales explained from $13 \%$ to $31 \%$ of the variance in the self-focus and self-regulatory measures. As would be expected, given its definition in terms of thoughts (as opposed to overt actions), the Preoccupation subscale showed the most consistent pattern of statistically significant unique relationships with the self-focus and self-regulation variables. The statistically significant results suggested that preoccupation-related action orientation is associated with focusing more on both public and private aspects of the self, experiencing social anxiety and depression, and the occurrence of intrusive thoughts while working on tasks. The Hesitation scale also showed consistent relationships with interference from competing tasks, but not with interference from self-relevant thoughts.

\section{Relationship of the Revised ACS Subscales With Personality and Affective Variables}

Because many traditional personality and motivational variables can be subsumed within the structure of the Big Five personality factors (Barrick \& Mount, 1991), regression models were used to see if a set of predictors consisting of measures of the Big Five and of dispositional affect would explain most of the variance in the revised ACS subscales. If so, then the action-state orientation construct would contribute little new information to our understanding. The results of these analyses are presented in Table 6. The Big Five plus dispositional affect as a block explained $13 \%$ of the variance in preoccupation subscale scores, $28 \%$ of the variance in Hesitation subscale scores, and $6 \%$ of the variance in Volatility subscale scores. Thus, although the overlap between the revised ACS subscales and a combination of the Big Five and dispositional affect is statistically significant, the majority of the variance in the revised ACS subscales is not accounted for by these measures. Importantly, the $R^{2}$ values are smaller for regressions with the revised ACS subscales as dependent variables than for regressions with the original ACS-90 subscales as dependent variables (.02 on average), demonstrating that the revised ACS subscales are more independent of the Big Five and dispositional affect than are the original ACS-90 subscales. Emotional stability made the strongest contribution to the prediction of the revised ACS subscales (see Table 6), being significantly positively related to all three ACS

Table 6

Regression of Personality and Affective Variables on Revised Action Control Scale Subscales

\begin{tabular}{|c|c|c|c|c|c|c|c|c|}
\hline \multirow{2}{*}{$\begin{array}{l}\text { Dependent } \\
\text { variable }\end{array}$} & \multicolumn{6}{|c|}{ Standardized regression coefficient $(\beta)$} & \multirow[b]{2}{*}{$R^{2}$} & \multirow[b]{2}{*}{$F(6,232)$} \\
\hline & Agree & Depend & Em Stb & Extra & Intel & Affect & & \\
\hline Preoccupation & -0.06 & -0.04 & $0.35^{* * *}$ & 0.05 & 0.08 & 0.05 & .13 & $5.81^{* * *}$ \\
\hline Hesitation & $-0.12 \dagger$ & $0.38 * * *$ & $0.22 * * *$ & $0.15^{*}$ & 0.04 & 0.09 & .28 & $15.25^{* * *}$ \\
\hline Volatility & $<0.01$ & 0.07 & $0.18 * *$ & $<0.01$ & 0.07 & 0.02 & .06 & $2.28^{*}$ \\
\hline
\end{tabular}

Note. $\quad N=239$. Agree $=$ agreeableness; Depend $=$ dependability; $E m$ Stb $=$ emotional stability; Extra $=$ extraversion; Intel $=$ intellect; Affect $=$ dispositional affect.

$\dagger p<.10$ (marginally significant). ${ }^{*} p<.05 .{ }^{* *} p<.01 . \quad * * * p<.001$. 
subscales, indicating that individuals who were more emotionally stable tended to be more action-oriented. The Hesitation subscale was also significantly predicted by dependability $(\beta=0.38, p<$ $.001)$ and by extraversion $(\beta=0.16, p=.05)$, indicating that more conscientious and outgoing individuals tended to be better at initiating actions.

Social desirability was significantly positively correlated with responses on all three ACS subscales (for Preoccupation, $r=.34$, $p<.001$; for Hesitation, $r=.37, p<.001$; and for Volatility, $r=$ $.10, p=.05$ ), indicating that being action-oriented was associated with socially desirable responding. This finding occurred in spite of Kuhl's (1994a) intention to reduce socially desirable responding by using response alternatives that reflect behaviors and not traits. These significant correlations are likely a reflection of the value society places on action-oriented behaviors such as maintaining mental focus, achieving tasks, and making progress in the pursuit of goals.

\section{Relationships of the Revised ACS Subscales With Job Attitudes and Ratings of Work Performance}

Finally, we wanted to determine if the ACS subscales were valuable as predictors of organizationally relevant variables. Multiple regression models were used to determine the extent to which the three revised ACS subscales uniquely predicted job attitudes and supervisor ratings of work performance and OCBs. Preliminary analyses showed that the revised ACS subscales were significantly correlated with several participant demographic and work characteristics, including age, gender, organization tenure, and hours worked per week (additional detail on these relationships is available from James M. Diefendorff). In addition, previous research has shown that a variety of demographic and personality variables relate to job attitudes and work performance. To more stringently test the relationship between the revised ACS subscales and work-related variables, a hierarchical regression approach was used. Predictors were added in three blocks: (a) age, sex, organization tenure, number of hours worked per week, and the rated consistency of one's job with career interests, (b) the Big Five personality dimensions, and (c) the three revised ACS subscales. Using this approach provided a conservative test of the influence of action-state orientation on job attitudes and job performance, because any variance in the criterion variables associated with the demographic and personality predictors was not included in the tests of the ACS effects.

The results of the hierarchical regression analyses are summarized in Table 7. The top portion of this table reports the results of the tests of the job attitude variables. For all four job attitudes examined, the demographic variables significantly predicted differences in attitudes, explaining from $9 \%$ to $30 \%$ of the variance. The Big-Five personality dimensions significantly predicted three job attitude variables (job involvement-role, job involvementsetting, and job satisfaction), explaining an additional $10 \%$ to $11 \%$ of the variance. The revised ACS subscales significantly incremented the prediction of the first two blocks only for the work centrality variable, explaining an additional $4 \%$ of the variance. Most of the prediction in this block was due to the Hesitation subscale, which had a significant regression coefficient $(\beta=0.20$, $p=.02$ ). Thus, action-oriented individuals, as indicated by their ability to effectively initiate activities, appear to see work as a more central aspect of their life.

Although these findings with regard to the ACS are not particularly impressive, they appear to be a function of the conservative approach taken in our regression models. In fact, when the revised ACS subscales are entered in the second step and the Big Five dimensions are entered in the third step of the regression equations, the block of ACS subscales accounts for a significant amount of variance in all four job attitudes and has five significant regression

Table 7

Hierarchical Regression of Work Variables on the Revised Action Control Scale (ACS) Subscales, Controlling for Demographics and Personality

\begin{tabular}{|c|c|c|c|c|c|c|c|c|c|c|}
\hline \multirow[b]{2}{*}{ Dependent variable } & \multirow[b]{2}{*}{$n$} & \multicolumn{2}{|c|}{$\begin{array}{c}\text { Step 1: } \\
\text { Demographics }\end{array}$} & \multicolumn{2}{|c|}{ Step 2: Big Five } & \multicolumn{2}{|c|}{$\begin{array}{c}\text { Step 3: } \\
\text { ACS subscales }\end{array}$} & \multirow{2}{*}{$\begin{array}{l}\text { Preoccupation } \\
(\beta)\end{array}$} & \multirow{2}{*}{$\begin{array}{l}\text { Hesitation } \\
\quad(\beta)\end{array}$} & \multirow{2}{*}{$\begin{array}{l}\text { Volatility } \\
\qquad(\beta)\end{array}$} \\
\hline & & $\Delta R^{2}$ & $F^{\mathbf{a}}$ & $\Delta R^{2}$ & $F^{\mathrm{b}}$ & $\Delta R^{2}$ & $F^{c}$ & & & \\
\hline \multicolumn{11}{|l|}{ Job attitudes } \\
\hline \multicolumn{11}{|l|}{ Job involvement } \\
\hline Role & 222 & .30 & $18.47^{* * *}$ & .10 & $6.68 * * *$ & .02 & $2.35 \dagger$ & -0.08 & $0.12 \dagger$ & $0.10^{\dagger}$ \\
\hline Setting & 222 & .21 & $11.70^{* * *}$ & .11 & $7.11^{* * *}$ & .02 & 1.91 & 0.01 & -0.03 & $0.14^{*}$ \\
\hline Job satisfaction & 224 & .26 & $15.29 * * *$ & .11 & $7.33 * * *$ & .01 & 1.58 & -0.10 & 0.07 & 0.08 \\
\hline Work centrality & 224 & .09 & $4.34 * * *$ & .03 & 1.26 & .04 & $3.50^{*}$ & -0.03 & $0.20^{*}$ & $0.13+$ \\
\hline \multicolumn{11}{|l|}{ Supervisor ratings } \\
\hline $\begin{array}{l}\text { Job performance } \\
\text { OCB }\end{array}$ & 128 & .07 & 1.87 & .02 & 0.37 & .08 & $3.45^{*}$ & -0.17 & $0.36^{* *}$ & 0.05 \\
\hline Altruism & 128 & .03 & 0.78 & .03 & 0.86 & .09 & $4.21 * *$ & $-0.18 \uparrow$ & $0.31^{* *}$ & $0.19^{*}$ \\
\hline Civic-Virtue & 128 & .07 & 1.90 & .02 & 0.48 & .11 & $5.02 * *$ & -0.08 & $0.40 * * *$ & 0.11 \\
\hline Conscientiousness & 128 & .02 & 0.54 & .01 & 0.15 & .08 & $3.27 *$ & $-0.20 \dagger$ & $0.24^{*}$ & $0.18 \dagger$ \\
\hline Courtesy & 128 & .03 & 0.86 & .01 & 0.29 & .06 & $2.59+$ & $-0.21 \dagger$ & $0.25 *$ & 0.12 \\
\hline Sportsmanship & 128 & .11 & $2.92^{*}$ & .07 & $1.97 \dagger$ & .02 & 1.14 & 0.10 & 0.12 & 0.03 \\
\hline
\end{tabular}

Note. $\quad$ OCB $=$ Organizational Citizenship Behavior Questionnaires.

${ }^{\mathrm{a}} d f=5,119 .{ }^{\mathrm{b}} d f=5,112 .{ }^{\mathrm{c}} d f=3,111$.

$\dagger p<.10$ (marginally significant). $* p<.05 . \quad * * p<.01 . \quad * * * p<.001$ 
coefficients indicating unique contributions of individual subscales. These results indicate that a large amount of the variance in job attitudes accounted for by the revised ACS subscales is shared with the Big Five.

As the results in the bottom half of Table 7 demonstrate, the revised ACS subscales were very successful in uniquely predicting supervisor ratings of in-role performance and OCBs. The increment in $R^{2}$ attributable to the block of three ACS subscales was statistically significant for supervisor ratings of in-role job performance and three domains of OCBs: altruism, civic-virtue, and conscientiousness (see Table 7). The statistically significant increments in $R^{2}$ ranged in value from .08 to .11 , an increase that is also practically meaningful, especially when considering the large number of demographic and personality variables entered in Blocks 1 and 2 . These results suggest that action-oriented individuals are more likely to receive high performance evaluations than state-oriented individuals, both for performing duties specified in their job description and for more voluntary "good citizen" behavior. An interesting finding for the supervisor ratings is that the size of the change in $R^{2}$ values for the ACS block is four to five times larger than that of the Big Five. This result dramatically shows that action-state orientation has utility in predicting supervisor ratings of job performance, above and beyond commonly used personality measures. Furthermore, it should be noted that we repeated these analyses using the original ACS-90 subscales, and in every instance the revised ACS subscales accounted for more variance in supervisor ratings of job performance and OCBs than did the original scales.

The pattern of statistical significance for the regression coefficients shows that most of the unique variance accounted for in the performance domains is due to the hesitation component of actionstate orientation. Although the Hesitation subscale demonstrated the greatest degree of overlap with the Big Five and dispositional affect ( $28 \%$ shared variance), it was still the strongest predictor of supervisor ratings of in-role performance and OCBs, even after controlling for the effects of the Big Five and several demographic variables. An unexpected finding was that the regression coefficients for the Preoccupation subscale were negatively related to five of the six performance criteria, three of which approached significance ( $p<.10$; see Table 7 ). These results suggest that state-oriented processing associated with the preoccupation dimension may be related to effective job performance and OCBs.

\section{General Discussion}

The study results have implications both for the measurement of action-state orientation in general, and for the use of the action-state orientation construct in models of volitional behavior in work settings. These implications are discussed in detail in the following sections.

\section{Implications for Measurement}

Overall, the results from the present study provide a muchneeded first step in demonstrating the usefulness of the individual difference construct of action-state orientation in the workplace. Consistent with Schwab's (1980) recommendation to address construct validity issues prior to using a measure widely, we demonstrated that carefully examining the construct validity of a measure results in a better understanding of the underlying dimensions being measured and a sounder interpretation of subsequent findings. On the bases of the CFAs using the revised set of items, we found convincing support for a three-factor solution, supporting the idea of three separate components of action-state orientation. Although future research should further examine the comparability of the full versus the revised ACS, the present results indicate that by excluding 14 poorly performing items, the resulting three subscales had less overlap with each other and with existing personality and affective disposition measures than did the original subscales. In addition, the revised subscales were better able to predict real-world outcomes such as job performance and OCBs.

One may question the advisability of dropping items from scales that already have a relatively low number of items. As noted earlier, the revised subscales do have slightly lower internal consistency reliability estimates than do the original subscales (see Note at bottom of Table 4). However, we believe that (a) the internal consistency estimates based on alpha are likely underestimates given that the items are dichotomous and do not meet tau-equivalence conditions (Cortina, 1993, p. 101), and (b) the slight drop in internal consistency that may have occurred is offset by improved definition of the three latent factors.

To explain the second point further, we turn to LISREL estimates of the intercorrelations among the three latent factors. These correlations provide information that would not be evident in an inspection of the correlations among the subscale scores reported in Table 4. The intercorrelations of the latent factors based on the original set of items are quite high, particularly for the preoccupation-hesitation relationship, which had a standardized covariance of .93 . In contrast, the covariance between the preoccupation and hesitation latent factors drops substantially to a value of .68 for the revised item model. Our interpretation of this result is that the two constructs are more clearly differentiated from each other in the revised item model because fewer of the indicators have substantial contamination from nonprimary factors. Similar evidence of increased differentiation is seen in the comparison of the correlations of the latent Volatility factor with the Preoccupation and Hesitation factors for the full item model, which showed covariances of .63 and .79 , respectively, versus the reduced item model, which showed covariances of .07 and .39 , respectively.

Even though the revised ACS-90 showed lower than ideal reliability, the current study demonstrated a compelling number of theoretically consistent relationships with other variables. However, future research in organizations may benefit from the development of additional action-state orientation items, in order to address issues of reliability. These items may also be tailored more specifically to the work context. However, this attempt should be made with care, in order to preserve the meaning of, and distinctions between, the preoccupation, hesitation, and volatility constructs.

\section{Implications for Industrial-Organizational Psychology}

The regression results further demonstrated a pattern of findings consistent with Kuhl's (1994b) theory of action-state orientation. None of the cognitive ability measures examined was significantly predicted by any of the revised ACS subscales. Furthermore, it was demonstrated that the Big Five with dispositional affect accounted for, at most, $28 \%$ of the variance in any one ACS subscale. Together these findings imply that action-state orientation is not redundant with existing cognitive ability and personality measures.

Overall, the revised Volatility subscale demonstrated the weakest relationships with the dependent variables included in this 
study. This finding is not surprising given the difficulty in identifying well-performing items for this scale, and the eventual use of only six items in the analyses reported. The Preoccupation subscale demonstrated the strongest relationships with the selfregulatory and self-focus variables. This finding is consistent with the definition of the Preoccupation subscale as focusing more on internal states and thoughts than the Hesitation and Volatility subscales. Yet the Hesitation scale did show several significant negative correlations with measures of distraction or interference from competing tasks, indicating that action-oriented individuals stay on task and avoid disruptions better (see Table 5). These results are consistent with recent research showing that initiating actions makes competing information less accessible in memory (Gollwitzer \& Schaal, 1998; Goschke \& Kuhl, 1993).

The revised Hesitation subscale demonstrated the strongest relationships with job performance and OCB ratings. This finding makes sense given the emphasis of the hesitation component on the overt action of initiating activities in a timely fashion. The fact that ratings of job performance and OCBs were provided by an independent source (supervisors) is evidence that work behaviors, rather than thoughts or emotions, are the key link between Hesitation-related action orientation and job performance. This result also suggests that the correlation of the ACS subscales with social desirability is not a competing explanation for the ability of ACS scales to predict job behaviors, which were rated by supervisors.

A closer look at the relationship between supervisor ratings and the ACS subscales shows that the Hesitation subscale was consistently positively related to performance ratings as expected. However, unexpectedly, the Preoccupation subscale was generally negatively related to ratings of performance. This finding, although contrary to our original expectations, is consistent with some work by Beckmänn (Beckmänn, 1994; Beckmänn \& Kazén, 1994), who suggested that depending on the role and type of task, a state orientation may be beneficial. State-oriented individuals, as assessed by the Preoccupation subscale, may be more cautious, diligent, and thoughtful than action-oriented individuals, which may benefit work performance for jobs that require careful decision-making and as rated by supervisors who value thoroughness. It is important for many jobs, however, that persons who are thoughtful in the planning stage then proceed to use their plans (as assessed by the Hesitation subscale). These findings argue for the usefulness of distinguishing among the three ACS dimensions and suggest that differing combinations of the action-state components may be optimal for the performance of different types of jobs. Future research should attempt to substantiate the specific processes relating both the Preoccupation and Hesitation subscales to work performance and to identify the specific job contexts under which different levels of action-state orientation will optimize performance.

The finding that supervisor ratings of job performance and OCBs were strongly predicted by the revised ACS subscales, even after controlling for several demographic variables and the Big Five personality dimensions, suggests that the three components of action-state orientation may be useful in explaining important organizational outcomes. Consistent with Kuhl's (1992) suggestion, it may be that the volitional constructs assessed by the ACS are more closely tied to actual performance than more distally related constructs such as personality. This is not to say that action-state orientation is more important or more useful than the Big Five, but rather that it can complement the Big Five and make substantive contributions to our understanding of many work- related issues. Action-state orientation, and volitional issues more generally, are underutilized in much applied research today (Frese \& Zapf, 1994). A major contribution of this article is to highlight the value of investigating volitional issues in the workplace.

In conclusion, we believe that the present findings provide an important first step in introducing the concept and measurement of the components of action-state orientation to applied settings. Although more research is needed to further validate and refine the ACS and to replicate our current findings, we believe that with the size of the samples used in the current study and the breadth of the variables examined, the present investigation provides a base for further examining volitional issues and their impact in the workplace. Furthermore, our aggregate results support the assertion made in the Introduction that more attention should be paid to issues of goal-striving in the study of work performance. Future theoretical development of work motivation models should give equal consideration to issues of goal setting and goal-striving.

\section{References}

Austin, J. T., \& Vancouver, J. B. (1996). Goal constructs in psychology: Structure, process, and content. Psychological Bulletin, 120, 338-375.

Barrick, M. R., \& Mount, M. K. (1991). The Big Five personality dimensions and job performance: A meta-analysis. Personnel Psychology, 44, 1-26.

Beck, A. T. (1978). Beck Depression Inventory (Rev. ed.) Philadelphia: Center for Cognitive Therapy.

Beckmänn, J. (1994). Volitional correlates of action vs. state orientation. In J. Kuhl \& J. Beckmänn (Eds.), Volition and personality: Action versus state orientation (pp. 155-166). Seattle, WA: Hogrefe \& Huber.

Beckmänn, J., \& Kazén M. (1994). Action and state orientation and the performance of top athletes. In J. Kuhl \& J. Beckmänn (Eds.), Volition and personality: Action versus state orientation (pp. 439-451). Seattle, WA: Hogrefe \& Huber.

Broadbent, D. E., Cooper, P. F., FitzGerald, P., \& Parkes, K. R. (1982). The Cognitive Failures Questionnaire (CFQ) and its correlates. British Journal of Clinical Psychology, 21, 1-16.

Brunstein, J. C., \& Olbrich, E. (1985). Personal helplessness and action control: Analysis of achievement-related cognitions, self-assessments, and performance. Joumal of Personality and Social Psychology, 48, 1540-1551.

Cortina, J. M. (1993). What is coefficient alpha? An examination of theory and applications. Journal of Applied Psychology, 78, 98-104.

Crowne, D. P., \& Marlowe, D. (1960). A new scale of social desirability independent of psychopathology. Joumal of Consulting Psychology, 24, 349-354.

Diefendorff, J. M., Lord, R. G., Hepburn, E. T., Quickle, J. S., Hall, R. J., \& Sanders, R. E. (1998). Perceived self-regulation and individual differences in selective attention. Journal of Experimental Psychology: Applied, 4, 228-247.

Fenigstein, A., Scheier, M. F., \& Buss, A. H. (1975). Public and private self-consciousness: Assessment and theory. Journal of Consulting and Clinical Psychology, 43, 522-527.

Frese, M., \& Zapf, D. (1994). Action as the core of work psychology: A German approach. In M. D. Dunnette, L. M. Hough, \& H. C. Triandis (Eds.), Handbook of industrial and organizational psychology, Vol. 4 (2nd ed., pp. 271-340). Palo Alto, CA: Consulting Psychologists Press.

Goldberg, L. R. (1992). The development of markers for the Big-Five factor structure. Psychological Assessment, 4, 26-42.

Gollwitzer, P. M., \& Brandstätter, V. (1997). Implementation intentions and effective goal pursuit. Journal of Personality and Social Psychology, 73, 186-199.

Gollwitzer, P. M., \& Schaal, B. (1998). Metacognition in action: The importance of implementation intentions. Personality and Social Psychology Review, 2, 124-136.

Goschke, T., \& Kuhl, J. (1993). Representation of intentions: Persisting activation in memory. Journal of Experimental Psychology: Learning, Memory, and Cognition, 19, 1211-1226. 
Heckhausen, H., \& Gollwitzer, P. (1987). Thought contents and cognitive functioning in motivational vs. volitional states of mind. Motivation and Emotion, 11, 101-120.

Hollenbeck, J. R., \& Klein, H. J. (1987). Goal commitment and the goal-setting process: Problems, prospects, and proposals for future research. Journal of Applied Psychology, 72, 212-220.

Hu, L., \& Bentler, P. M. (1999). Cutoff criteria for fit indexes in covariance structure analysis: Conventional criteria versus new alternatives. Structural Equation Modeling, 6, 1-55.

Ironson, G. H., Smith, P. C., Branick, M. T., Gibson, W. M., \& Paul, K. B. (1989). Construction of a job in general scale: A comparison of global, composite, and specific measures. Joumal of Applied Psychology, 74, 193-200.

Jöreskog, K., \& Sörbom, D. (1989). LISREL 7: User's reference guide [Computer software manual]. Chicago: SSI.

Jöreskog, K., \& Sörbom, D. (1993). LISREL 8.14 and PRELIS for Windows [Computer software manual]. Chicago: SSI.

Kamin, A. M. (1999). Job satisfaction and job performance: A process perspective. Unpublished doctoral dissertation, University of Akron, Akron, Ohio.

Kane, M. J., Hasher, L., Stoltzfus, E. R., Zacks, R. T., \& Connelly, S. L. (1994). Inhibitory attentional mechanisms and aging. Psychology and Aging, 9, 103-112.

Kanfer, R., Dugdale, B., \& McDonald, B. (1994). Empirical findings on the action control scale in the context of complex skill acquisition. In J. Kuhl \& J. Beckmänn (Eds.), Volition and personality: Action versus state orientation (pp. 61-77). Seattle, WA: Hogrefe \& Huber.

Karoly, P. (1993). Mechanisms of self-regulation: A systems view. Annual Review of Psychology, 44, 23-52.

Klinger, E., \& Murphy, M. D. (1994). Action orientation and personality: Some evidence on the construct validity of the Action Control Scale. In J. Kuhl \& J. Beckmänn (Eds.), Volition and personality: Action versus state orientation (pp. 79-92). Seattle, WA: Hogrefe \& Huber.

Kuhl, J. (1981). Motivational and functional helplessness: The moderating effect of state versus action orientation. Journal of Personality and Social Psychology, 40, 155-170.

Kuhl, J. (1985). Volitional mediators of cognition-behavior consistency: Self-regulatory processes and action versus state orientation. In J. Kuhl \& J. Beckmänn (Eds.), Action control: From cognition to behavior (pp. 101-128). New York: Springer-Verlag.

Kuhl, J. (1986a). Human motivation: From decision making to action control. In B. Brehmer, H. Jungerman, P. Lourens, \& G. Sevon (Eds.), New directions in research on decision making (pp. 5-28). New York: Elsevier Science.

Kuhl, J. (1986b). Motivation and information processing: A new look at decision making, dynamic change, and action control. In R. M. Sorrentino \& E. T. Higgins (Eds.), Handbook of motivation and cognition (pp. 404-434). New York: Guilford Press.

Kuhl, J. (1992). A theory of self-regulation: Action versus state orientation, self-discrimination, and some applications. Applied Psychology: An Intermational Review, 41(2), 97-129.

Kuhl, J. (1994a). Action versus state orientation: Psychometric properties of the action control scale (ACS-90). In J. Kuhl \& J. Beckmänn (Eds.), Volition and personality: Action versus state orientation (pp. 47-59). Seattle, WA: Hogrefe \& Huber.

Kuhl, J. (1994b). A theory of action and state orientations. In J. Kuhl \& J. Beckmänn (Eds.), Volition and personality: Action versus state orientation (pp. 9-46). Seattle, WA: Hogrefe \& Huber.

Kuhl, J., \& Beckmänn, J. (Eds.). (1985). Action control: From cognition to behavior. New York: Springer-Verlag.

Kuhl, J., \& Beckmänn, J. (Eds.). (1994). Volition and personality: Action versus state orientation. Seattle, WA: Hogrefe \& Huber.

Kuhl, J., \& Goschke, T. (1994). A theory of action control: Mental subsystems, modes of control, and volitional conflict-resolution strategies. In J. Kuhl \& J. Beckmänn (Eds.), Volition and personality: Action versus state orientation (pp. 93-123). Seattle, WA: Hogrefe \& Huber.

Kuhl, J., \& Helle, L. (1986). Motivational and volitional determinants of depression: The degenerated-intention hypothesis. Journal of Abnormal Psychology, 95, 247-251.

Kuhl, J., \& Helle, P. (1994). Motivational and volitional determinants of depression: The degenerated-intention hypothesis. In J. Kuhl \& J. Beckmänn (Eds.), Volition and personality: Action versus state orientation (pp. 283-296). Seattle, WA: Hogrefe \& Huber.

Kuhl, J., \& Kazén, M. (1994a). Self-discrimination and memory: State orientation and false self-ascription of assigned activities. Journal of Personality and Social Psychology, 66, 1103-1115.

Kuhl, J., \& Kazén, M. (1994b). Volitional aspects of depression: State orientation and self-discrimination. In J. Kubl \& J. Beckmänn (Eds.), Volition and personality: Action versus state orientation (pp. 297-315). Seattle, WA: Hogrefe \& Huber.

Kuhl, J., \& Kazén-Saad, M. (1989). Volition and self-regulation: Memory mechanisms mediating the maintenance of intentions. In W. A. Hershberger (Ed), Volitional action (pp. 387-407), New York: Elsevier Science.

Kuhl, J., \& Kraska, K. (1989). Self-regulation and metamotivation: Computational mechanisms, development, and assessment. In R. Kanfer, P. L. Ackerman, \& R. Cudeck (Eds.), Abilities, motivation, and methodology (pp. 343-374). Hillsdale, NJ: Erlbaum.

Latham, G. P., \& Locke, E. A. (1991). Self-regulation through goal setting. Organizational Behavior and Human Decision Processes, 50, 212-247.

Lewin, K., Dembo, T., Festinger, L., \& Sears, P. S. (1944). Level of aspiration. In J. M. Hunt (Ed.), Personality and the behavior disorders (Vol. 1, pp. 333-378). New York: Ronald Press.

Lord, R. G., \& Levy, P. E. (1994). Moving from cognition to action: A control theory perspective. Applied Psychology: An International Re. view, 43, 335-398

Paullay, I. M., Alliger, G. M., \& Stone-Romero E. F. (1994). Construct validation of two instruments designed to measure job involvement and work centrality. Journal of Applied Psychology, 79, 224-228.

Podsakoff, P. M., MacKenzie, S. B., Moorman, R. H., \& Fretter, R. (1990). Transformational leader behaviors and their effects on followers' trust in leader, satisfaction, and organizational citizenship behaviors. Leadership Quarterly, 1, 107-142.

Sarason, I. G., Sarason, B. R., Keefe, D. E., Hayes, B. E., \& Shearin, E. N. (1986). Cognitive interference: Situational determinants and traitlike characteristics. Joumal of Personality and Social Psychology, 51, 215-226.

Schwab, D. P. (1980). Construct validity in organizational behavior. Re. search in Organizational Behavior, 2, 3-43.

Strang. H. (1994). Performance-inducing influence of action and state orientation: Applying control theories to processes in sports. In J, Kuhl \& J. Beckmänn (Eds.), Volition and personality: Action versus state orientation (pp. 453-465). Seattle, WA: Hogrefe \& Huber

Strean, M. L. (1999). Action-state orientation and goal striving in the context of self-set goals. Unpublished doctoral dissertation, University of Akron, Akron, Ohio.

Tabachnick, B. G., \& Fidell, L. S. (1996). Using multivariate statistics. New York: HarperCollins.

Wechsler, D. (1981). Manual for the Wechster Adut Intelligence ScaleRevised. New York: Psychological Corporation.

Weitz, J. (1952). A neglected concept in the study of job satisfaction. Personnel Psychology, 5, 201-205.

Williams, L. J., \& Anderson, S. E. (1991). Job satisfaction and organizational commitment as predictors of organizational citizenship and in-role behaviors. Journal of Management, 17, 601-617. 


\section{Appendix}

Item Wordings and Factor Loadings $\left(\lambda_{x}\right)$ for the Three-Factor Model, Full Item Set

\begin{tabular}{|c|c|}
\hline Factor loading & Item \\
\hline & Preoccupation subscale \\
\hline .37 & $\begin{array}{l}\text { 1. When I have lost something that is very valuable to me and I can't find it anywhere; } \\
\text { A. I have a hard time concentrating on something else } \\
\text { B. I put it out of my mind after a little while }\end{array}$ \\
\hline .58 & $\begin{array}{l}\text { 4. If I've worked for weeks on one project and then everything goes completely wrong with the project: } \\
\text { A. It takes me a long time to adjust myself to it } \\
\text { B. It bothers me for a while, but then I don't think about it anymore }\end{array}$ \\
\hline .41 & $\begin{array}{l}\text { 7. When I'm in a competition and have lost every time: } \\
\text { A. I can soon put losing out of my mind } \\
\text { B. The thought that I lost keeps running through my mind }\end{array}$ \\
\hline .61 & $\begin{array}{l}\text { 10. If I had just bought a new piece of equipment (for example a tape deck) and it accidentally fell on the floor and was } \\
\text { damaged beyond repair: } \\
\text { A. I would manage to get over it quickly } \\
\text { B. It would take me a long time to get over it }\end{array}$ \\
\hline .56 & $\begin{array}{l}\text { 13. If I have to talk to someone about something important and, repeatedly, can't find him or her at home: } \\
\text { A. I can't stop thinking about it, even while I'm doing something else } \\
\text { B. I easily forget about it until I see the person }\end{array}$ \\
\hline .41 & $\begin{array}{l}\text { 16. When I've bought a lot of stuff at the store and realize when I get home that I've paid too much-but I can't get my money } \\
\text { back: } \\
\text { A. I can't usually concentrate on anything else } \\
\text { B. I easily forget about it }\end{array}$ \\
\hline .54 & $\begin{array}{l}\text { 19. When I am told that my work has been completely unsatisfactory: } \\
\text { A. I don't let it bother me for too long } \\
\text { B. I feel paralyzed }\end{array}$ \\
\hline .48 & $\begin{array}{l}\text { 22. If I'm stuck in traffic and miss an important appointment: } \\
\text { A. At first, it's difficult for me to start do anything else at all } \\
\text { B. I quickly forget about it and do something else }\end{array}$ \\
\hline .43 & $\begin{array}{l}\text { 25. When something is very important to me, but I can't seem to get it right: } \\
\text { A. I gradually lose heart } \\
\text { B. I just forget about it and do something else }\end{array}$ \\
\hline .78 & $\begin{array}{l}\text { 28. When something really gets me down: } \\
\text { A. I have trouble doing anything at all } \\
\text { B. I find it easy to distract myself by doing other things }\end{array}$ \\
\hline .80 & $\begin{array}{l}\text { 31. When several things go wrong on the same day: } \\
\text { A. I usually don't know how to deal with it } \\
\text { B. I just keep on going as though nothing had happened }\end{array}$ \\
\hline .74 & $\begin{array}{l}\text { 34. When I have put all my effort into doing a really good job on something and the whole thing doesn't work out: } \\
\text { A. I don't have too much difficulty starting something else } \\
\text { B. I have trouble doing anything else at all }\end{array}$ \\
\hline
\end{tabular}

Hesitation subscale

.812 . When I know I must finish something soon:

A. I have to push myself to get started

B. I find it easy to get it done and over with

.725 . When I don't have anything in particular to do and I am getting bored:

A. I have trouble getting up enough energy to do anything at all

B. I quickly find something to do

828 . When I am getting ready to tackle a difficult problem:

A. It feels like I am facing a big mountain that I don't think I can climb

B. I look for a way that the problem can be approached in a suitable manner

11. When I have to solve a difficult problem:

A. I usually don't have a problem getting started on it

B. I have trouble sorting things out in my head so that I can get down to working on the problem

14. When I have to make up my mind about what I am going to do when I get some unexpected free time:

A. It takes me a long time to decide what I should do during this free time

B. I can usually decide on something to do without having to think it over very much

17. When I have work to do at home:
A. It is often hard for me to get the work done

B. I usually get it done right away

20. When I have a lot of important things to do and they must all be done soon:

A. I often don't know where to begin

B. I find it easy to make a plan and stick with it 
Appendix (continued)

\begin{tabular}{|c|c|c|c|}
\hline & & Factor loading & Item \\
\hline & & .58 & $\begin{array}{l}\text { 23." When there are two things that I really want to do, but I can't do both of them: } \\
\text { A. I quickly begin one thing and forget about the other thing I couldn't do } \\
\text { B. It's not easy for me to put the other thing I couldn't do out of my mind }\end{array}$ \\
\hline & & .91 & $\begin{array}{l}\text { 26. When I have to take care of something important which is also unpleasant: } \\
\text { A. I do it and get it over with } \\
\text { B. It can take a while before I can bring myself to it }\end{array}$ \\
\hline & & .80 & $\begin{array}{l}\text { 29. When I am facing a big project that has to be done: } \\
\text { A. I often spend too long thinking about where I should begin } \\
\text { B. I don't have any problems getting started }\end{array}$ \\
\hline & & .50 & $\begin{array}{l}\text { 32. When I have a boring assignment: } \\
\text { A. I usually don't have any problem getting through it } \\
\text { B. I sometimes can't get moving on it }\end{array}$ \\
\hline & & .91 & $\begin{array}{l}\text { 35. When I have an obligation to do something that is boring and uninteresting: } \\
\text { A. I do it and get it over with } \\
\text { B. It can take a while before I can bring myself to do it }\end{array}$ \\
\hline
\end{tabular}

Volatility subscale

3. When I have learned a new and interesting game:

A. 1 quickly get tired of it and do something else

B. I can really get into it for a long time

$-.05 \quad 6 .^{\mathrm{a}}$ When I'm working on something that's important to me:

A. I still like to do other things in between working on it

B. I get into it so much that I can work on it for a long time

$.039 .^{a}$ When I'm watching a really good movie

A. I get so involved in the film that I don't even think of doing anything else

B. I often want to get something else to do while I'm watching the move

$.50 \quad 12$, When 1 have been busy for a long time doing something interesting (for example, reading a book or working on a project):

A. I sometimes think about whether what I'm doing is really worthwhile

B. I usually get so involved in what I'm doing that I never think to ask whether it's worthwhile

15. When I read an article in the newspaper that interests me:

A. I usually remain so interested in the article that I read the entire article

B. I still often skip to another article before I've finished the first one

$18{ }^{a}$ When I'm on vacation and having a good time:

A. After a while, I really feel like doing something completely different

B. I don't even think about doing anything else until the end of vacation

39 21. When one of my co-workers brings up an interesting topic for discussion:

A. It can easily develop into a long conversation

B. I soon lose interest and want to go do something else

59 24. When I am busy working on an interesting project:

A. I need to take frequent breaks and work on other projects

B. I can keep working on the same project for a long time

$1627 .^{\mathrm{a}}$ When I am having an interesting conversation with someone at a party:

A. I can talk to him or her the entire evening

B. I prefer to go do something else after a while

$-.10 \quad 30{ }^{a}$ When it tums out that I am much better at a game than the other players:

A. I usually feel like doing something else

B. I really like to keep playing

.82 33. When I read something I find interesting:

A. I sometimes still want to put the article down and do something else

B. I will sit and read the article for a long time

36. When I am trying to learn something new that I want to leam;

A. I'll keep at it for a long time

B. I often feel like I need to take a break and go do something else for a while

Note. The items are from Volition and Personality: Action Versus State Orientation (pp. 57-59), by J. Kuhl and J. Beckmän, 1994, Seattle, WA: Hogrefe \& Huber. Copyright 1994 by Hogrefe \& Huber Publishers, Seattle, Toronto, Göttingen, Bern. Reprinted with permission. Item scoring is reported in Kuhl (1994a).

a Item was dropped from the revised scale.

Received July 30, 1998

Revision received May 21, 1999

Accepted May 21, 1999 